\title{
Robert Challe, Journal d'un voyage aux Indes orientales (du 24 février 1690 au 10 août)
}

\section{Franco Piva}

\section{(2) OpenEdition}

1 Journals

\section{Edizione digitale}

URL: https://journals.openedition.org/studifrancesi/40723

DOI: 10.4000/studifrancesi.40723

ISSN: 2421-5856

\section{Editore}

Rosenberg \& Sellier

\section{Edizione cartacea}

Data di pubblicazione: 1 juillet 2004

Paginazione: 195-196

ISSN: 0039-2944

\section{Notizia bibliografica digitale}

Franco Piva, «Robert Challe, Journal d'un voyage aux Indes orientales (du 24 février 1690 au 10 août)», Studi Francesi [Online], 142 (XLVIII | I) | 2004, online dal 30 novembre 2015, consultato il 09 septembre 2021. URL: http://journals.openedition.org/studifrancesi/40723 ; DOI: https://doi.org/10.4000/ studifrancesi.40723

Questo documento è stato generato automaticamente il 9 septembre 2021.

\section{(c) 9 (i) $\Theta$}

Studi Francesi è distribuita con Licenza Creative Commons Attribuzione - Non commerciale - Non opere derivate 4.0 Internazionale. 


\title{
Robert Challe, Journal d'un voyage aux Indes orientales (du 24 février 1690 au 10 août)
}

\author{
Franco Piva
}

\section{NOTIZIA}

ROBERT CHALLE, Journal d'un voyage aux Indes orientales (du 24 février 1690 au 10 août). Texte publié et commenté par Frédéric DELOFFRE et Jacques POPIN. Nouvelle édition augmentée, Paris, Mercure de France, 2002, «Le Temps retrouvé», 2 voll. di pp. 612 e 566.

La prima edizione moderna integrale del Journal de voyage aux Indes orientales di Robert Challe apparve, ad opera di Frédéric Deloffre e Mélahat Menemencioglu, nel 1979; la seconda, «mise à jour et augmentée», ad opera degli stessi editori, qualche anno dopo, nel 1983. Fu subito una sorpresa per la straordinarietà del documento e la qualità, anche letteraria, della scrittura. Da allora l'interesse per Challe ha continuato a crescere, così come è cresciuta la conoscenza dello scrittore, di cui si è riusciti a poco a poco a ricostruire l'identità e la personalità ed al quale, negli anni successivi, sono state attribuite altre opere importanti: oltre alle Illustres Françaises, che Deloffre aveva riproposto fin dal 1959, i Mémoires e, soprattutto, le Difficultés sur la religion proposées au Père Malebranche che, a mano a mano che se ne approfondiva la lettura, hanno assunto sempre più la dimensione di un'opera rivelazione, fondamentale per capire non solo l'itinerario spirituale di Challe, che a sua volta si è rivelato sempre più scrittoresimbolo, ma anche un'epoca, quella della "crise de conscience», di cui Challe fu uno dei più coscienti esponenti. Anche l'interesse per il Journal aux Indes si è progressivamente approfomdito grazie alle ricerche degli studiosi che hanno scoperto tutta una serie di documenti che hanno permesso di capire meglio l'opera di Challe ed il contesto in cui essa è nata. Particolarmente importante, da questo punto di vista, è stata la scoperta di una versione primitiva deI Journal, composta au jour le jour, all'epoca del viaggio e 
quindi in grado di farci meglio capire il lavoro effettuato dallo scrittore sul testo primitivo per arrivare alla versione finale.

Challe essendo ormai riconosciuto come uno scrittore di prima grandezza, era in qualche modo logico che, dopo le Illustres Françaises, anche il Journal venisse prima o poi proposto in un'edizione economica, alla portata di un pubblico potenzialmente ampio, e comunque non specialista. È quanto hanno fatto Frédéric Deloffre, il grande scopritore di Challe, e Jacques Popin con questa edizione che non è una semplice ripresa delle edizioni precedenti, ma, come fanno giustamente notare gli Editori, «une édition vraiment nouvelle». Non solo perché il testo e l'annotazione sono stati accuratamente rivisti alla luce delle conoscenze che sono state via via acquisite, ma perché il significato stesso del Journal è stato ripensato sulla scorta della più approfondita conoscenza dello scrittore cui la critica è pervenuta dopo anni di appassionato ed intenso lavoro di ricostruzione e di analisi, e, d'altra parte, delle considerazioni sulle ragioni che hanno spinto Challe a riprendere a distanza di anni uno scritto, di natura in qualche modo ufficiale e tecnica quale era o doveva essere all'inizio il Journal, per farne sempre più una sorta di journal intime, nel quale, al di là delle informazioni spesso soprendentemente lucide, sull'altro che Challe viene via via scoprendo, s'incontrano i pensieri, le riflessioni, le paure di un uomo che, confrontandosi con le cose e le persone che incontra, incontra se stesso, e incontrando se stesso incontra e rappresenta l'uomo del suo tempo: un uomo, come è spesso Challe, désemparé, alla riœrca di un ubi consistam che gli sfugge continuamente, e che intanto si dibatte tra comico e tragico, tra banalità e sublimità, da ognuno di questi aspetti della realtà e di sé traendo, con lucidità, i frammenti di quell'essere strano, e per molti versi, incomprensibile che è l'uomo. Nella scoperta di Challe, della sua vita, della sua personalità e nell'affascinante viaggio alla scoperta dell'altro e dell'uomo di fine Seicento-inizio Settecento che è, in fondo, il Journal, il lettore è guidato dall'ampia Introduzione e dall'abbondante annotazione di cui gli editori hanno provveduto questa edizione per molti versi esemplare. 